MATHEMATICA, 63 (86), $\mathrm{N}^{\circ}$ 2, 2021, pp. 222-231

\title{
ON A SECOND-ORDER DIFFERENTIAL INCLUSION WITH CERTAIN INTEGRAL AND MULTI-STRIP BOUNDARY CONDITIONS
}

\author{
AURELIAN CERNEA
}

\begin{abstract}
We study a second-order differential inclusion with integral and multi-strip boundary conditions defined by a set-valued map with nonconvex values. We obtain an existence result and we prove the arcwise connectedness of the solution set of the considered problem.
\end{abstract}

MSC 2010. 34A60, 34B10, 34B15.

Key words. Differential inclusion, boundary value problem, measurable selection.

\section{REFERENCES}

[1] B. Ahmad, A. Alsaedi, M. Alsulami and S.K. Ntouyas, Second-order ordinary differential equations and inclusions with a new kind of integral and multi-strip boundary conditions, Differ. Equ. Appl., 11 (2019), 183-202.

[2] J.P. Aubin and H. Frankowska, Set-valued Analysis, Birkhäuser, Basel, 1990.

[3] A. Cernea, Some remarks on a fractional differential inclusion with non-separated boundary conditions, Electron. J. Qual. Theory Differ. Equ., 45 (2011), 1-14.

[4] A. Cernea, Some remarks on a multi point boundary value problem for a fractional order differential inclusion, J. Appl. Nonlinear Dyn., 2 (2013), 151-160.

[5] A.F. Filippov, Classical solutions of differential equations with multivalued right hand side, SIAM J. Control Optim., 5 (1967), 609-621.

[6] K. Kuratowski and C. Ryll-Nardzewski, A general theorem on selectors, Bull. Acad. Pol. Sci., 13 (1965), 397-403.

[7] S. Marano, Fixed points of multivalued contractions with nonclosed, nonconvex values, Atti Accad. Naz. Lincei Rend. Lincei Mat. Appl., 5 (1994), 203-212.

[8] S. Marano and V. Staicu, On the set of solutions to a class of nonconvex nonclosed differential inclusions, Acta Math. Hungar., 76 (1997), 287-301.

Received January 7, 2020

Accepted August 31, 2020
University of Bucharest

Faculty of Mathematics and Computer Science 010014 Bucharest, Romania

E-mail: acernea@fmi.unibuc.ro

https://orcid.org/0000-0002-9174-9855

DOI: 10.24193/mathcluj.2021.2.08 